\title{
Reply to Tsurutani et al.'s comment on "Storming the Bastille: the effect of electric fields on the ionospheric F-layer" by Rishbeth et al. (2010)
}

\author{
R. A. Heelis ${ }^{1}$, J. J. Makela ${ }^{2}$, and Su. Basu ${ }^{3}$ \\ ${ }^{1}$ William B. Hanson Center for Space Sciences, The University of Texas at Dallas, P.O. Box 830688, Richardson, TX 75083, \\ USA \\ ${ }^{2}$ Department of Electrical and Computer Engineering, University of Illinois at Urbana-Champaign, Urbana, IL 61801, USA \\ ${ }^{3}$ Institute for Scientific Research, Boston College, Chestnut Hill, MA 02467, USA \\ Correspondence to: R. A. Heelis (heelis@utdallas.edu)
}

Despite the opening paragraph of the commentary by Tsurutani et al. (2013), it is not clear to which "fundamentally incorrect statements" in Rishbeth et al. (2010) they are referring.

The commentary makes three points and we will discuss these in the order in which they appear in Tsurutani et al. (2013).

First is a discussion of how total electron content (TEC) enhancements to 200 or more units may appear in the expanded crests of the anomaly, which are located near $25^{\circ}-$ $30^{\circ}$ magnetic latitude. Tsurutani et al. (2013) point out that these enhancements result from the presence of an outward meridional $\boldsymbol{E} \times \boldsymbol{B}$ drift originating from a prompt penetration electric field. Rishbeth et al. (2010) agree and cite previous work by Tsurutani et al. (2004), Yin et al. (2004), Basu et al. (2007) and Lin et al. (2005, 2009), all of which show that the appropriate TEC enhancements arise in the presence of enhanced outward meridional $\boldsymbol{E} \times \boldsymbol{B}$ drifts. In their comment, Tsurutani et al. (2013) state, "The main point we wish to make from this figure is that the CHAMP data show that the EIAs become displaced from their normal location $\left(\sim \pm 10^{\circ}\right)$ poleward with increasing time." This point is well recognized and appears in Rishbeth et al. (2010) by citing previous work, such as “... Tsurutani et al. (2004) describe a so-called super-fountain effect that creates a poleward displacement of the equatorial anomaly peaks in the presence of enhanced outward meridional $\boldsymbol{E} \times \boldsymbol{B}$ drifts..." We conclude that no fundamentally incorrect statements appear in Rishbeth et al. (2010) on this topic.

Tsurutani et al. (2013) move forward with their commentary by describing computer simulations of the effects of en- hanced meridional $\boldsymbol{E} \times \boldsymbol{B}$ drifts. Much of this work is a recapitulation of previously published work, but it appears that the point is to show that TEC peaks appear at $25^{\circ}$ to $30^{\circ}$ magnetic latitude in such simulations. It may also be appropriate to point out that equatorward meridional winds can also influence the vertical drift motion and associated TEC enhancements at middle latitudes (Lin et al., 2005), and that such winds have been shown to be significant during the particular event simulated by Tsurutani et al. (2013) for their commentary (Basu et al., 2005).

Tsurutani et al. (2013) present these simulations to address the question of where the plasma originates and, in this regard, the authors make conclusions that can be easily tested. It is valuable to recall that Rishbeth et al. (2010) state that “... TEC enhancements at latitudes beyond 25 degrees cannot generally be attributed to transport from the equator." The work of Tsurutani et al. (2013) assumes a zonal electric field of $4 \mathrm{mV} \mathrm{m}^{-1}$, which generously translates to an upward drift of $130 \mathrm{~m} \mathrm{~s}^{-1}$, for a duration of $2 \mathrm{~h}$. If we assume a peak plasma density near $350-\mathrm{km}$ altitude, then a flux tube through this location at $25^{\circ}$ magnetic latitude has an apex height above $1800 \mathrm{~km}$. For plasma at the equator, at 350 $\mathrm{km}$ altitude, moving under the influence of an $\boldsymbol{E} \times \boldsymbol{B}$ drift of $130 \mathrm{~m} \mathrm{~s}^{-1}$, it will take over $3 \mathrm{~h}$ to arrive at $25^{\circ}$ magnetic latitude. In their comment Tsurutani et al. (2013) perhaps obfuscate the statement above made by Rishbeth et al. (2010) by later invoking transport from $\pm 20^{\circ}$. If $20^{\circ}$ is the location that they wish to identify as the plasma source for an enhancement at $25^{\circ}$, there would be no argument. What is potentially misleading is the statement by Tsurutani et al. (2013) that "Plasma originally from latitudes lower than where the 
'displaced' TEC peaks are observed has been transported to the peaks and elsewhere" As pointed out in the discussion of advection by Rishbeth et al. (2010), $\boldsymbol{E} \times \boldsymbol{B}$ drifts preserve a frozen-in magnetic flux. Thus, for a given location, time and ExB drift history, as specified for example by Tsurutani et al. (2013), there is a discrete location identified by a magnetic flux line from which the plasma has originated. There can be no accumulation of plasma from a range of locations (Rishbeth and Hanson, 1974) and there is no ambiguity in the simple calculation executed above. Rishbeth et al. (2010) considered transport times in a more general context including those associated with storm enhanced density, and we do not find evidence presented by Tsurutani et al. (2013) that show them to be fundamentally incorrect.

In the third part of their comment, Tsurutani et al. (2013) address the mechanisms by which enhanced upward plasma drifts can produce enhanced TEC values. Again, they reproduce a discussion that has been put forward some years ago by Balan et al. (1998). Rather than repeat that discussion, Rishbeth et al. (2010) describe the process with the words "Rather, upward plasma motions in the presence of solar production act locally (within 5 degrees latitude) to increase TEC significantly by raising the existing plasma to a region of lower plasma loss rate while additional ionization is produced below."

In summary, we are left at a loss to discover where any fundamentally incorrect statements arise in the work of Rishbeth et al (2010). Tsurutani et al. (2013) state that “... solar production of ionization leads to the enhanced densities of the displaced peaks" and in their final comments they refer to the mechanism as "... increased production". These statements could be misunderstood, since the ionization production rate does not change as the result of changes in $\boldsymbol{E} \times \boldsymbol{B}$ drifts. Rishbeth et al. (2010), more accurately point out that the main action of upward $\boldsymbol{E} \times \boldsymbol{B}$ drifts is to reduce the plasma loss rate, and it is this reduction in the loss rate that allows large TEC values to be attained. This fundamental aspect is at work in all the simulations that have been cited.

If there is any disagreement in the commentary of Tsurutani et al. (2013) and the work of Rishbeth et al. (2010), it is not that plasma is transported, but from where. Rishbeth et al. (2010) point out that simple mathematics will allow the degree to which transport from one location to another is responsible for the TEC enhancements. But they also point out that the plasma transport preserves a frozen-in magnetic flux and that one cannot accumulate the TEC from multiple locations at some other fixed location. Computer simulations, including those by Tsurutani et al. (2013), show that TEC enhancements occur in the presence of $\boldsymbol{E} \times \boldsymbol{B}$ drifts of about $100 \mathrm{~m} \mathrm{~s}^{-1}$ with a duration of about $2 \mathrm{~h}$. In this case, it is straightforward to show that TEC enhancements at $35^{\circ}$ are produced by the upward and poleward motion in sunlight of plasma originating near $31^{\circ}$. Likewise, enhancements at $25^{\circ}$ are produced by upward and poleward motion in sunlight of plasma originating near $20^{\circ}$.
We conclude that Tsurutani et al. (2013) have not identified any fundamentally incorrect statements made by Rishbeth et al. (2010). In fact, they have further emphasized that a more rigorous analysis of computer model outputs and the application of fundamental physical principles, as suggested by Rishbeth et al. (2010), are most likely to improve our understanding.

\section{References}

Balan, N., Batista, I. S., Abdu, M. A., MacDougall, J., and Bailey, G. J.: Physical mechanism and statistics of occurrence of an additional layer in the equatorial ionosphere, J. Geophys. Res., 103, 29169-29181, doi:10.1029/98JA02823, 1998.

Basu, Su., Basu, S., Makela, J. J., Sheehan, R. E., MacKenzie, E., Doherty, P., Wright, J. W., Keskinen, M. J., Pallamraju, D., Paxton, L. J., and Berkey, F. T.: Two components of ionospheric plasma structuring at midlatitudes observed during the large magnetic storm of October 30, 2003, Geophys. Res. Lett., 32, 12, doi:10.1029/20004GL021669, 2005.

Basu, S., Basu, Su., Rich, F. J., Groves, K. M., MacKenzie, E., Coker, C., Sahai, Y., Fagundes, P. R., and Becker-Guedes, F.: Response of the equatorial ionosphere at dusk to penetration electric fields during intense magnetic storms, J. Geophys. Res., 112, A08308, doi:10.1029/2006JA012192, 2007.

Lin, C. H., Richmond, A. D., Heelis, R. A., Bailey, G. J., Lu, G., Liu, J. Y., Yeh, H. C., and Su, S.-Y.: Theoretical study of the low- and midlatitude ionospheric electron density enhancement during the October 2003 superstorm: Relative importance of the neutral wind and the electric field, J. Geophys. Res., 110, A12312, doi:10.1029/2005JA011304, 2005.

Lin, C. H., Richmond, A. D., Liu, J. Y., Bailey, G. J., and Reinisch, B. W.: Theoretical study of new plasma structures in the lowlatitude ionosphere during a major magnetic storm, J. Geophys. Res., 114, A05303, doi:10.1029/2008JA013951, 2009.

Rishbeth, H. and Hanson, W. B.: A comment on 'plasma pile-up' in the F-region, J. Atmos. Terr. Phys., 36, 703-706, 1974.

Rishbeth, H., Heelis, R. A., Makela, J. J., and Basu, S.: Storming the Bastille: the effect of electric fields on the ionospheric F-layer, Ann. Geophys., 28, 977-981, doi:10.5194/angeo-28-977-2010, 2010.

Tsurutani, B., Mannucci, A., Iijima, B., Abdu, M. A., Sobral, J. H. A., Gonzalez, W., Guarnieri, F., Tsuda, T., Saito, A., Yumoto, K., Fejer, B., Fuller-Rowell, T. J., Kozyra, J., Foster, J. C., Coster, A., and Vasyliunas, V. M.: Global dayside ionospheric uplift and enhancement associated with interplanetary electric fields, J. Geophys. Res., 109, A08302, doi:10.1029/2003JA010342, 2004.

Tsurutani, B. T., Mannuccci, A. J., Verkhoglyadova, O. P., and Lakhina, G. S.: Comment on "Storming the Bastille: the effect of electric fields on the ionospheric F-layer" by Rishbeth et al. (2010), Ann. Geophys., 31, 145-150, doi:10.5194/angeo31-145-2013, 2013.

Yin, P., Mitchell, C. N., Spencer, P. S. J., and Foster, J. C.: Ionospheric electron concentration imaging using GPS over the USA during the storm of July 2000, Geophys. Res. Lett., 31, L12806, doi:10.1029/2004GL019899, 2004. 